\title{
Partners, Not Peers: Defining Boundaries and Expectations in Student Partnerships
}

\author{
Holly Pelnar, Grace Reyes, Kiran Sehgal, and * Leslie Cameron, Department of Psychological \\ Science, Carthage College, USA \\ (All authors contributed equally to this work) \\ Contact: Icameron@carthage.edu
}

In this reflection, one current student (Holly Pelnar), two former students (Grace Reyes and Kiran Sehgal), and one faculty member (Leslie Cameron) from Carthage College, a small liberal arts college in the United States, reflect on their experiences in student-faculty partnerships in the scholarship of teaching and learning (SoTL). From the faculty perspective, one of the most compelling aspects of conducting research in SoTL with undergraduate students as partners ( $\mathrm{SaP}$ ) is that the focus of the research is the students and their learning. Crucially, students also offer a unique perspective as they have relevant lived experience. From the student perspective, working as a student partner is motivating because we are working on topics that are relevant to our own learning and we have an opportunity to work closely with faculty in a unique research environment. In this essay we have collaboratively reflected on our experiences working together and identified challenging aspects of the partnership that we think could be improved to enhance the experience.

\section{BACKGROUND}

In Fall 2015, I, Leslie Cameron, was granted a one-course teaching release to work with a group of psychology students on SoTL projects. Although I had worked with many undergraduates in disciplinary research for nearly 20 years, I had never included them in SoTL research. I was particularly excited about the opportunity to work with students on research that was directly relevant to them. I invited five students, including Grace and Kiran, to be a part of this one-term trial research experience because I knew each of them to be strong students in other contexts. The work culminated in a presentation at a regional conference on the teaching of psychology (Cameron et al., 2016) and was the topic of several student theses and on-campus presentations.

More recently I invited Holly to be a student partner on a SoTL project. She has worked with me for several years and is currently revising her senior thesis for publication.

Our process in developing this reflection involved multiple Skype meetings to discuss $\mathrm{SaP}$ and our experiences. Between meetings we wrote sections of the reflection independently and commented on each other's writing. 


\section{REFLECTIONS}

\section{Grace Reyes}

I was a third-year undergraduate student when I was working as a student partner, and I am now teaching English in Spain. My project involved creating and administering assessments at the beginning and end of a first-year course, Introduction to Psychological Science (which we will refer to as "Intro" for the remainder of this paper), to evaluate what students had learned during the semester. Despite some of the issues I outline below, this remains one of the most fulfilling projects I participated in while in college thanks to the close relationships I developed with my fellow students and Dr. Cameron and the dynamic nature of the work.

In addition to my work as a student partner, I was also one of the Psychological Science Departmental Fellows. My responsibilities included attending faculty meetings, running study sessions for students in Intro, and other administrative duties. Sometimes, the working relationship between myself and Dr. Cameron was a challenge for me. When we met to discuss our SoTL project we were research partners, but in departmental meetings I was the undergraduate fellow and she, the head of the department at the time, was my boss. At times I was unsure about the appropriate level of formality of our interactions, because our relationship changed depending on the situation.

My unique position in the department, due in part to my SaP work, also complicated my relationship with fellow students. When analyzing the first-day assessments in my SoTL research, I found myself rolling my eyes at freshman responses, forgetting that just a few years before I would have struggled with some of the questions. Moreover, I knew that many who were challenged by the first-day assessment were not attending the study sessions where they could have gotten help with difficult concepts or gained a deeper understanding of the material.

Through reflection, it has become clear that juggling multiple roles is what might have led to my own uncertainty while working on the project. I felt pressure to perform a balancing act, presenting myself in one way to first year Intro students, another way to the SoTL team, and in an entirely different way while working with Dr. Cameron and the other professors in the department.

The balancing act also came into play when I studied abroad and grappled with my level of involvement while not on campus. I was abroad during the spring of my junior year, the semester after embarking on our SoTL work. Our plan was to finish our research within the semester, but we jumped at an opportunity to present at a regional conference in the second semester. While we had discussed my responsibilities prior to my departure, I found it difficult to balance what I felt was being asked of me and not wanting to make the long-distance collaboration difficult for Dr. Cameron (which I worked to avoid by not asking too many questions, being available to Skype as often as possible, etc.).

Sometimes I felt ill-equipped or unmotivated to complete some of the tasks I was responsible for while trying to be fully immersed in my program in Spain. For example, my computer did not have a copy of SPSS but I had to run t-tests to analyze data, and, in order to attend meetings with the others in the group, I had to stay up late to accommodate their schedules and the time difference. I felt like I was expected to know much more than I did 
regarding research methods or SoTL research in general. It would have been helpful if Dr. Cameron had been more explicit about expectations, as Holly explains in depth below.

Some of my closest friends were SoTL team members, and having an outlet to discuss our research in an informal setting was helpful. My friendship with Kiran, which she describes below, developed tremendously during our semester doing SoTL work because we were able to speak frankly about our challenges and celebrate our accomplishments together. Having a network of former student researchers and setting aside time for them to meet with us would have alleviated some of my stress, especially when I was feeling uncertain.

\section{Kiran Sehgal}

I began working as a student partner during my second year at Carthage College, and I am currently a master's student in public health at the University of Wisconsin-Milwaukee. We decided that my research topic would be metacognition (i.e., thinking about thinking), a topic I had read about in high school. We explored and found a lack of good metacognitive skills in Intro students.

I was the youngest member of the team and, in retrospect, I realize that I faced "imposter syndrome". Giving a name to this set of symptoms (as was done during the orientation to my master's program) has taught me to grow through the challenges I face. I have created the mantra: "You are meant to be in the program because everyone's background is unique," but as a sophomore I did not have this tool. A constant worry I had was not living up to Dr. Cameron's expectations. For example, she assigned reading and writing a literature review on metacognition. Doing this for the first time intimidated me, and although I knew I had to overcome this challenge since it was a requirement for other projects like my senior thesis, my lack of confidence deterred me from getting started. Through reflection I realized that learning to conduct SoTL research is like learning to ride a bike, and the first step is getting on the bike. Seeing other team members begin their work and coming to recognize that Dr. Cameron's invitation to join the team was a reflection of her confidence in me, my confidence grew. It grew further when Dr. Cameron trusted my judgement to invite another student (Alison) to join our SoTL team when one student was unable to participate. Thus, I tried to take off the training wheels knowing I had the support of the team.

Inviting Alison enhanced my sense of belonging. She was already friends with other members on the team and they included me. They also reassured me that it was okay to feel intimidated and to make mistakes, and they normalized asking for help from professors. Initially, dedicating energy to new friendships was not a priority to me, and I often worked independently. However, worrying about maintaining confidentiality with student survey data and transcribing it was difficult and anxiety-provoking. I found that sharing food and conversation with my teammates before and after meetings was a key to overcoming my anxiety about my work. Specifically, my friendship with Grace was extremely helpful, and we learned how to support each other more than just in research. A pivotal moment in our friendship was during mid-December after a research meeting. We walked out together into falling snow from the lab with candy canes in our hands that Dr. Cameron had given us and chatted all the way to the library. We were surprised that we had not exchanged phone numbers before then, but recognized this was because we both had many campus 
commitments. This friendship has flourished and endured. The investment in friendships paid off by increasing team rapport, which contributed to our success as a group.

Although this support was present, as I rode my bike I still wondered if I was going in the right direction and at an appropriate pace. It was difficult to recognize at every moment if I was on the right track even though I knew I could keep pedaling my way. Regardless of experience level, the timing of the bike ride of research goals and deadlines is a challenge I realize that I continue to face. I have felt uncertainty in the beginning of other bike rides for professional and academic endeavors I have taken since then, but this experience shows I am capable of continuing on my own path.

\section{Holly Pelnar}

I am currently a senior at Carthage College. I started working in Dr. Cameron's lab in the summer after my freshman year on a project that focused on helping students communicate more clearly about data, and specifically on graph literacy. Our goal is to develop better strategies for teaching students to interpret and communicate about graphical data.

When I began working with Dr. Cameron, I was thrilled to have the opportunity to advance my skills as a researcher as well as be able to work with her one-on-one. However, I was met with several challenges connected to my own insecurities. Given that I started my work as a freshman, I was surrounded by upperclassmen and worried that I was expected to provide the same quality of work that they were. I was afraid that Dr. Cameron would be comparing my work to theirs, despite the gaps in experience. Even now as an upperclassman, I often forget that I am not expected to know everything; the important thing is that I am completing my tasks to the best of my current ability. Though Dr. Cameron communicates that she considers us as partners in the work we are doing, I have trouble feeling that way. I fear that I will become a burden if I ask for too much or take up too much of her time. Moreover, I tend to believe that the success of our project depends on me since, in my mind, she has other, more important responsibilities to focus on. In this project, I am the only student partner so I feel as if I have no one with whom I can share my worries and perceived pressure. I often forget that Dr. Cameron is here as my partner in this project and is happy to help me if I need it. Although they have not vanished entirely, one of the ways I reduce these worries is by addressing them with Dr. Cameron. In fact, writing this paper has really helped me feel more comfortable talking to her candidly about these challenges. It also helped me feel more confident when Grace and Kiran assured me that it is completely natural to feel insecure. Had I not found a way to break down the barrier and speak openly with Dr. Cameron, my self-efficacy and motivation to tackle other research challenges would be greatly reduced.

As a student, I believe that I bring a unique perspective to the project, but, in doing so, I risk exposing some shortcuts that I use while doing my schoolwork. When brainstorming for our project, I admitted to Dr. Cameron that, sometimes, the problem is not in students' ability to understand graphical data, but rather, in their willingness to try to do so. The results of my thesis revealed that many students do not seem to have an efficient strategy for viewing and interpreting data. We (yes, I do this too) will simply gloss over a figure or graph because developing a complete understanding of it does not seem worth the effort, especially if we know that we are not going to be tested on it. Though I was reluctant to offer this insight, my 
unique perspective as a student helped us to improve our methodology. I believe that our project would not have been as successful had Dr. Cameron and I not combined our different perspectives.

Finally, Kiran and I both found it stressful knowing that Dr. Cameron planned on utilizing our findings to inform her future teaching. While it is very exciting to be involved in applied research, I worry that if I make a mistake or draw an incorrect conclusion, other students could be negatively affected. It would be a waste of time and energy (not to mention embarrassing!) if I proposed a method that was ultimately ineffective. In a recent conversation, Dr. Cameron reminded me that as my faculty partner, she would guide the application of our findings, which helped alleviate these worries.

\section{Leslie Cameron}

While collaborating on this reflection with students and another one with faculty colleagues (Cameron \& Campbell, 2020), I have found that my understanding of what it means to be in partnership with students has deepened.

In our first conversation, Grace, Kiran, Holly, and I began to tackle the issue of a "power dynamic" that the students indicated was a challenge for them, and which surprised me. Although I recognized that students are not my peers, in that we are not the same in age, status, nor ability, I had selected these students because I thought so highly of them and thought we could be partners or co-investigators. As I reflected on this, I worried that I had inadvertently reinforced a power dynamic, by, for example, going by "Dr. Cameron." I deliberately chose to go by "Dr." early in my teaching career because, as a young female professor, the title made it easier for me to navigate my relationship with students. In more recent years, my self-concept as a teacher-scholar has solidified, and I feel that my title reflects my relevant scientific training, knowledge, and experience. As we discussed the issue of power, I worried that there was a counterproductive hierarchy in our relationship and wondered whether we could build a true partnership without breaking down that power dynamic. This led to some soul-searching as both partnership with students and my self-concept are important to me. Through our conversations, I have come to think that the students are partners in the sense that we work collaboratively as a team to articulate and address scientific problems of mutual interest and that we listen and value each other's perspectives even though we are not peers. For their part, the students ultimately articulated to me that it was the high expectations and their insecurities that were challenging for them, as they have described in this reflective essay. Again, I was surprised to learn about the insecurities of these talented students who I have held in such high regard. I was relieved that I had not reinforced an unproductive power dynamic.

I have come to the realization that the important work I need to do in improving these powerful learning experiences is to communicate to the students the difference between partners and peers. I expect commitment from the students, for them to complete tasks appropriate for undergraduate researchers and for them to work up to their potential, not mine. I have learned from working on this reflective essay with students that it would be helpful to students for me to be more explicit about our roles and my high, but reasonable and attainable, expectations of them. 


\section{CONCLUSION}

SoTL research conducted with SaP is a very powerful model and our experiences have affirmed our belief in its value. Grace balanced multiple roles while working as a student partner but found that support from fellow student researchers facilitated her SoTL experience. Kiran worked hard to overcome imposter syndrome and found that the effort she put in met Leslie's expectations. Holly realized that she could work more effectively if she held herself to more realistic standards. Although we conducted quality research, there was a mismatch between Leslie's expectations and the students' perceptions of them. To help students appreciate boundaries and expectations in student-faculty partnerships, we suggest that partners have explicit conversations about roles and responsibilities and the scope of the projects.

We worked on this writing project during the Covid-19 pandemic. All of our meetings were conducted via Skype from our homes and each meeting included some time spent talking about the pandemic as we were each experiencing it. This resulted in a relaxed and informal context for our work. We have agreed that the informality was positive and that it enhanced our work together. Grace, Kiran, and Holly all indicated that efforts to make meetings more informal, like bringing food to meetings, as Leslie typically does when we are in person, reduces stress and makes them feel more comfortable. We have explicitly addressed the issue of the hierarchy in our relationships and are coming to a better understanding of being partners, not peers. That is, the expectations we have for each other are commensurate with our knowledge and experience and we have a deeper appreciation of the value of our various perspectives. This writing project has solidified our relationships and reinforced the fact that we are, indeed, true partners.

\section{ACKNOWLEDGEMENTS}

Thanks to Dr. Cornelia Zerban for her contributions to this work and for contributing some data on the students' SaP experience. We also thank Patrick Engle, Alison Mackey, and Michael von Borstel for their contributions to our SoTL team and Carthage College Provost David Garcia for support.

\section{NOTES ON CONTRIBUTORS}

Leslie Cameron is Professor of Psychological Science at Carthage College.

Holly Pelnar is an undergraduate student at Carthage College.

Grace Reyes is an English teacher at Padington School.

Kiran Sehgal is a graduate student at the University of Wisconsin-Milwaukee Zilber School of Public Health. 


\section{REFERENCES}

Cameron, E. L. \& Campbell, C. (2020). Reflections on building a strong and genuine partnership with students in SoTL projects. Manuscript submitted for publication.

Cameron, E.L., Zerban, C., Engle, P., Mackey, A., Reyes, G., Sehgal, K., \& von Borstel, M. (2016, February). Student-faculty partnership in the scholarship of teaching and learning (SoTL). Presentation at the Annual Meeting of the Midwest Institute for Students and Teachers of Psychology, College of Du Page, Glen Ellyn, IL. 